University of Texas Rio Grande Valley

ScholarWorks @ UTRGV

School of Social Work

$12-2021$

\title{
Do nursing and pharmacy students practice what they preach on safe drug storage and disposal? A cross-sectional study
}

\author{
Tamara Al Rawwad \\ The University of Texas Rio Grande Valley \\ Patrici K. Schrader \\ Andrea Brooks \\ Lillian Duong \\ Douglas Thornton
}

Follow this and additional works at: https://scholarworks.utrgv.edu/sw_fac

Part of the Nursing Commons, and the Social Work Commons

\section{Recommended Citation}

Al Rawwad, T., Schrader, P. K., Brooks, A., Duong, L., \& Thornton, D. (2021). Do nursing and pharmacy students practice what they preach on safe drug storage and disposal? A cross-sectional study. Nurse education today, 107, 105143. https://doi.org/10.1016/j.nedt.2021.105143

This Article is brought to you for free and open access by ScholarWorks @ UTRGV. It has been accepted for inclusion in School of Social Work by an authorized administrator of ScholarWorks @ UTRGV. For more information, please contact justin.white@utrgv.edu, william.flores01@utrgv.edu. 
DO NURSING AND PHARMACY STUDENTS PRACTICE WHAT THEY PREACH ON SAFE DRUG STORAGE AND DISPOSAL? A CROSS-SECTIONAL STUDY

Tamara Al Rawwad*

School of Social Work

University of Texas Rio Grande Valley

1201 W. University Drive, Edinburg, TX 78539

Email: tamara.alrawwad@utrgv.edu

Phone: 956-665-3577

Patrici K. Schrader

College of Nursing

University of Houston at Sugar Land

14000 University Blvd.

Sugar Land, Texas 77479

Email: pkschrader@uh.edu

Phone: 832-842-8216

Andrea Brooks

College of Nursing

University of Houston at Katy

22400 Grand Cir. Room: $306 \mathrm{H}$

Katy, TX 77449

Email: anbrook2@central.uh.edu

Phone: 832-842-8213

Lillian Duong

University of Houston College of $r$; arınacy

Email: Iduong2@central.uh.eru

Phone: 832-689-2718

Douglas Thornton

College of Pharmacy

University of Houston

Health 2 Building- Room 4055

Houston, TX 77204-5000

Email: jdthornt@central.uh.edu

Phone: 713-743-7358 
Funding statement: This work is supported by the Substance Abuse and Mental Health Services Administration (SAMHSA) via the Texas Health and Human Services Commission. The views and opinions contained in this research do not necessarily reflect those of SAMHSA, U.S. Department of Health and Human Services, or Texas Health and Human Services Commission, and should not be construed as such. 


\begin{abstract}
Background: Research has confirmed a lack of knowledge regarding the risks of unused medications including diversion, misuse, or accidental overdose among health care professionals (Arabia, 2020). Nurses and pharmacists are often who patients interact with the most regarding medications; therefore, early education on proper storage and disposal is vital (Bowen, Rotz, Patterson, \& Sen, 2017; Celio, Ninane, Bugnon, \& Schneider, 2018).
\end{abstract}

Objectives: The study's objective is to explore safe drug storage and disposal knowledge, attitudes, and practices of professional pharmacy (Pharm.D.) and nursing students.

Design: This research is an exploratory cross-sectional study from May to September 2019.

Methods: An anonymous online survey was administered to a purposi 'e s' mple of Pharm.D. and nursing students who were 18 years and older and enrolled in the site's acc edı 'd Pharm.D. and nursing programs $(\mathrm{N}=210)$. Responses were analyzed using descriptive statistics.

Results: Common disposal methods reported by students oi thei personal medications such as pills and liquids included discarding medications with the household rası. (range $30 \%$ to 55\%) and medication disposal products/bag (range 19\% to 28\%). More than 1a'. of the participants (50.4\%) had unused prescription medication at home, 35\% kept the medi atı $=$ or later use, and almost $20 \%$ of the participants reported sharing personal medicati ns $_{\text {vitı }}$ others.

Conclusion: Although the majority of stu dent par i cipants had adequate knowledge of the appropriate methods for safe drug disposal, few reported $\iota$ sing them for their own personal medications. The findings suggest there is a disconnect between the pr $\mathrm{r}_{i}$-ipants' knowledge of the appropriate methods of safe drug storage and disposal in a professional $\sim^{+}+\mathrm{i}_{\mathcal{O}}$ and their own practices. Further research is needed to explore and address the reasons for th tisconnect. Additionally, findings from this research will assist in the development of and/or the imnre vement of interdisciplinary educational materials among pharmacy and nursing students. 
Introc'ac or

In 2019, more than 4 billion prescriptioı, Jrugs were filled at pharmacies in the United States (Shahbandeh, 2020), and the total cost of $\uparrow$ res, ription drug sales was $\$ 507.9$ billion (Tichy et al., 2020). For many Americans, taking medicati on 1 . an essential daily routine. According to a survey conducted by the Centers for Disease Control a. 'd r - evention (CDC) in the years 2013-2016, almost half (48.49\%) of persons had taken at least , ne, rescription medication within the past 30 days (CDC, 2020; Martin, Hales, Gu, \& Ogden, 2019). , o ensure medications are effective and appropriately used, certain steps need to be taken: proper medication storage, disposal, and education on storage and disposal.

Previous research found that people tend to store their medication in the medicine cabinet, kitchen, and bedroom (Wieczorkiewicz, Kassamali, \& Danziger, 2013). However, these locations do not meet the required conditions of proper storage. Improper storage can cause changes to the medication's appearance, degradation, and/or a lower potency. 
Additionally, the dispensed and stored medications are not always consumed by the patient during the prescribed timeframe. A previous study found that two thirds of the dispensed medication were left unused, with more than $40 \%$ of patients citing improvement in health condition as the reason (Law et al., 2015). Unused prescriptions should not be viewed as leftover medication for later use. The availability of unused medication stored at home increases the risk of drug diversion, misuse, or accidental overdose, especially in children and young adults (McCabe, Teter, Boyd, Wilens, \& Schepis, 2018; Mitchell, Nolte, Turner, Hamby, \& Jones, 2018; Petrik, McNamara Voeschler, \& Blair, 2019; Schillie, Shehab, Thomas, \& Budnitz, 2009). The growing problem witı pre scription drug misuse is alarming among children, adolescents, and young adults, with tie $\iota_{2}$, three medication classifications misused being opioids, depressants, and stimulants (SAMH_ $1.2(15)$. The misuse of prescription stimulants posed a problem in the college setting, as $\mathrm{Kav}-$ ind Drake (2012) reported estimates of lifetime use ranging from $5-43 \%$ to reach des rec aca ${ }^{-1}$ emic achievement (Blevins, Stephens, \& Abrantes, 2017).

\section{Background}

Federal agencies, including Lrug Enforcement Administration (DEA), Food and Drug Administration (FDA), and l' 'II! ' a states Environmental Protection Agency (EPA), have recommendation on how patients should dish ise of their unused medications. These agencies recommend that patients bring their unused medicine to a collection site or to a Take-Back event. Because of the growing awareness of the national opioid pandemic, the Secure and Responsible Drug Disposal Act was implemented in 2014. Through the implementation of this act, there is an increase in options and access for patients to properly dispose of their controlled medication. Patients can choose to use a mail-back program or a collection receptacle for their unused controlled substances. Patients may also drop-off their medication to other locations such as participating retail pharmacy, narcotic treatment program, and hospital with an on-site pharmacy (Drug Enforcement Administration 2014). Another option is 
single-use disposal and drug deactivation system products. These products allow patients to safely dispose of medications at home and to lower the adverse effects of improper drug disposal on the environment (Bakshi, Korey, Fowler, \& Banga, 2018).

Besides the consumer, health care professionals such as nurses and pharmacists can make a large impact on addressing the need for proper medicine disposal. Studies have shown that educating patients on the importance of proper unused medication disposal methods, including specifically controlled substances, have greatly increased the likelihood of patients be, forming this action (Buffington, Lozicki, Alfieri, \& Bond, 2019).

As the healthcare professional who spends the mos $^{+}$u1 $\bullet$ with patients, nurses are important members of the healthcare team. They are in a prime pnsition tc educate patients on the importance of performing proper medicine disposal. Pharmacists, the ui ug experts, are another health care team member who has the responsibility of educatir, oatients regarding medication use, storage, and disposal. As the last healthcare professior $-1 p_{c}$ tients see, pharmacists are able to counsel patients on how to properly dispose of their unu: ea $\urcorner \mathrm{r}$ expired medicine. Therefore, both nurses and pharmacists are ideal for providing the prope- ec 'cation on medication disposal to patients.

While a number of tud $ə s$ exist in the United States and in other countries about safe drug storage and disposal knov'lf dge, attitudes, and practices, they are mostly limited to the general public. Research is scarce on the knowledge, attitudes, and practices of drug storage and disposal among health care students, such as pharmacy and nursing students, who are on the 'front lines' in health care settings. These students are the future healthcare professionals who will be interacting with patients, and it is imperative that they learn how to address the growing issue of unused expired medicine and its disposal. 
However, there have been no studies in the U. S. that examined nursing students' and pharmacy students' knowledge and attitudes, including their personal practice of safe drug storage and disposal. Therefore, this study explored the knowledge, attitudes, and practices of Nursing and pharmacy students on safe drug storage and disposal to increase the researchers' knowledge about the latter and to identify the need for education on these topics.

\section{Methods}

\section{Study Design}

This research was an exploratory, descriptive, and $\mathrm{cr}^{-}-$sectional study conducted from May 2020 to September 2020. An anonymous online surve." va: administered to a purposive sample of professional pharmacy and nursing students. - he tudy was approved by the university's Institutional Review Board (IRB).

\section{$\underline{\text { Participants }}$}

The target population inc. ' $d \in \mathcal{J}$ nursing and professional pharmacy students enrolled and attending a public universit $/$ in , 'ouston. Nursing students from three different undergraduate baccalaureate tracks: traditi nal Bachelors of Science in Nursing (BSN), Registered Nurse (RN) to BSN, and second degree BSN were recruited in collaboration with faculty in the College of Nursing at the university. Professional pharmacy students from first year through fourth year were recruited in collaboration with student organizations and class officers at the College of Pharmacy. The total number of students who received the survey from both colleges was 400 students.

\section{$\underline{\text { Instruments and Measures }}$}


The outcome measures in this study were the knowledge, attitude, and practice of nursing and professional pharmacy students regarding safe drug storage and disposal. The final survey instrument consisted of 41 items that were adopted or adapted from three different instruments and included a mix of open-ended questions and multiple-select questions. Thirty-three questions were adapted from previous studies of that examined safe drug storage and disposal. Table I, II, and III, in the appendices, show the specific questions adapted from each study. In Table I, the questions from Tong, Peake, and Braund (2011) study explored disposal practices for unused medications n community pharmacies. Table II has questions from Pankajkumar, Chacko, and Prakashkumar , 701 j) study, which explored the storage and disposal of medicines in homes of students. For Tat le $1 ., i, i$ has questions from Bataduwaarachchi, Thevarajah, and Weeraratne (2018) whı h w re over medication waste disposal practices from patients attending outpatient departm $\mathrm{n}^{+} s$ it a tertiary care institution. Table IV shows additional questions that were created by the , sir :ipa' investigator (PI). The items were divided into different sections. The first section covere $t$ the de.nographics of the participants. The following sections of the survey included items that measu e $h_{1}$. participants' opinion on prescriptions, over-the-counter

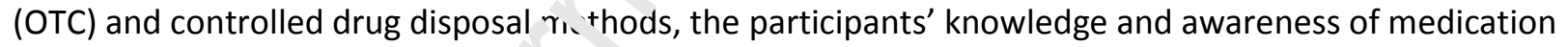
they are/have been taking, the int ' 7 ction with healthcare provider concerning their medication, the participants' storage pr. -tic ?, a d d the knowledge and practice of unused medication disposal.

\section{Procedure}

The initial survey was piloted on 9 professional pharmacy students for face validity. The feedback from the pilot testers indicated that grammar errors and additional clarification were needed to enhance the clarity of the questions. Pilot testers were excluded from participating in the final survey. Pharmacy student organization leaders and class officers distributed the survey through Listserv emails. Before beginning the survey, participants who met the inclusion criteria, which were Pharm.D or Nursing 
student, age 18 years or older, and a student attending the university, were directed to provide consent to participate in this study.

At the end of the survey, participants were offered the choice of providing their email address to enter a raffle to win one of five $\$ 50$ Amazon gift certificates. To enter their email address, participants were redirected to a different Qualtrics $@$ survey. Responses from the two surveys were not linked and maintained the participants' anonymity.

\section{Data}

Data were entered and coded, then descriptive statisti 's w re calculated for all survey items. All statistical analyses were conducted using SPS s version 27 (SPSS Inc., Chicago, IL, USA). The results are expressed as numbers and pe--entages presented in the forms of tables and graphs. In addition, the associations betweer var ables were determined by performing chisquare tests. A $p$-value $<0.05$ was considere a statistically significant difference in all analyses.

\section{Results}

Of all participants $(\mathrm{n}=210,13,(66 \%)$ were professional pharmacy students $(\mathrm{PharmD})$, and $71(34 \%)$ were nursing stuci nts. The majority of the participants (78.5\%) were females, and more than a third wer A ian 42.8\%). Almost half of the pharmacy students were in their third year of their profession: 1 ducation (44\%), and nearly two thirds of nursing students were enrolled in their second degree BSN program. Details are presented in Table 1.1 and Table 1.2.

When asked about their opinion on proper disposal of different forms of OTC unused and expired medications, the majority of pharmacy $(79.4 \%)$ and nursing $(80.4 \%)$ students chose a medication bin collected by a contractor as the most appropriate method to dispose of unused and expired medications. When asked about their opinion on proper disposal of Schedule II medications that included certain narcotic, stimulant, and depressant drugs, such as oxycodone, methylphenidate, and 
dextroamphetamine, $77.7 \%$ of pharmacy students and $73.2 \%$ nursing students chose a medication bin collected by a contractor as the most appropriate method. Similarly, medications bins collected by a contractor was chosen by both pharmacy (79.1\%) and Nursing students (73.2\%) as the most appropriate method to dispose of Schedule III prescription drugs, such as acetaminophen with codeine and hydrocodone. Details are presented in Table 2 below.

When students were asked if they received advice on safe medication storage, almost one third of both groups reported not receiving any advice (31.4\% of pharmacy stua: ints, $32.8 \%$ of nursing students). Almost half of PharmD (47\%) and more than two thirds i V/ung students (68.9\%) reported not receiving any advice on proper disposal of medications. Botı, oroups of students reported pharmacists as the main provider of advice and information $r_{t}$ ted to the storage of unused or expired medications. In regards to the source of advice on sift is r osal of medications, nursing students reported nurses as the main provider of advic $\left(3^{\prime}, .8 \%\right)$, and pharmacy students reported pharmacists as their main provider of advice on safe drug ci ‘ posal (82\%). Only one student in both groups reported receiving advice on safe drug disposal fror ' t'ieir physician. Details are presented in Table 3 below.

Nearly $40 \%$ of pharmacy эni nursing students who had medications at home reported storing their medications in the kitrite. aımost half of pharmacy students (46.5\%) and two thirds of nursing students (63.9\%) reported s sring their medications in medicine cabinet. The majority of students kept their medications in the original container (95.6\% pharmacy, $98.4 \%$ nursing). Surprisingly, almost $40 \%$ of pharmacy students, and $23 \%$ of nursing students reported storing their medications in an open place reachable by children. Additionally, two thirds of students in both groups reported storing unused medications with their other medications. See Table 4 below.

More than two thirds of the students in both groups (68\%) reported disposing of medications as they were without diluting or crushing them. The most frequent methods used by both pharmacy and 
nursing students surveyed was to dispose different forms of their unused and expired medication in a trash can or in a medication disposal product or bag. Details are provided in Table 4.

Almost all students from both groups were aware of indications of their medication $198.5 \%$ pharmacy students and $100 \%$ nursing students). The majority of the medications were tablets/capsule, and $76.5 \%$ and $76.9 \%$ of pharmacy and nursing students, respectively, reported obtaining their medications from a provider. Almost half of pharmacy students and 59\% of nursing students reported collecting all their prescribed medications from the pharmacy even if they lid not need some of it. Nearly $60 \%$ of pharmacy students and $43.8 \%$ of nursing students $r_{-\mu} \cdot r_{k} u$ having unused and leftover medications at home. The most frequent reasons reported bv buth pharmacy and nursing students for not using all their medications were excess prescribed amoı'n, change of treatment, health condition improved, past expiration date, side effects of the $m e c^{\prime \prime}$ at ons, and/or medication was discontinued by the prescriber.

When asked about the main reasrns i $r$ keeping their unused or leftover medications, $70.6 \%$ of pharmacy students and $50 \%$ of nursir $g$ s "luents reported keeping them in case they needed the medication later, $30.9 \%$ of pharr.ac, students and $34.6 \%$ of nursing students reported not wanting to waste medication, and $11.8^{\prime}$ o $f$ pr rarmacy students and $34.6 \%$ of nursing students were not sure of how to dispose of them. Twenty- wo percent of pharmacy students and $11.5 \%$ of nursing students who had medications at home reported sharing their medication with parents, partners or spouse, siblings, friends, or their children. See Table 5 for details.

\section{Discussion}

Most pharmacy and nursing students were knowledgeable about how to safely store their medications and dispose of them when they were finished. However, about a third of the students 
did not apply their knowledge of safe medication storage and disposal into their personal practice.

Additionally, about half of the students were not provided counseling by their healthcare providers at the time of prescribing or dispensing of their medication. The main source of counseling for medication storage and disposal was from pharmacists. The number of students not provided counseling is concerning. These findings are found to be lower than the study on patients receiving health care practitioner counseling on disposal ('va risco, Fleming, Bapat,

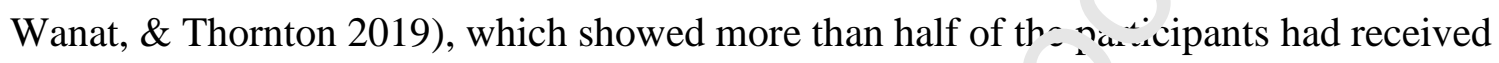
counseling from a professional. The results in this study als: showed that general practitioners were the main provider of the counseling while about onc , uarter was from pharmacists. Another study also showed that healthcare student. are able to acquire information on proper medication storage and disposal from mar..' sr urces. With more personal exposure to medication counseling, the students personal practic after graduation can be affected by their exposure to proper counseling from healthcare r``of ‘ ionals (Raja, Mohapatra, Kalaiselvi 2018).

Both groups, pharmacy $\hat{a} \cdot$ 'd nursing students, were storing unused medicine in their homes (59.5\% and 43.8\% ma.ively). This finding was particularly concerning since McCabe, Teter, Boyd, Wilens, anc Scnepis (2018) found that the most common source of prescription drug misuse among college students and graduate were obtained free from friends and relatives. Improper medication storage and disposal may have possible negative outcomes for the public in regards to untreated health conditions, growth of drug resistant bacteria, and narcotic or prescription drug misuse, as well as harm or death (Mitchell, Nolte, Turner, Hamby, \& Jones, 2018; Schillie, Shehab, Thomas, \& Budnitz, 2009). According to the FDA (2020), annually in the US, approximately 600,000 emergency department visits and 450,000 calls to poison control 
centers occur after a child has found and ingested leftover medication. Consequences are potentially severe.

Nurses and pharmacists are a primary source of patient education regarding medication practices on safe storage and disposal, and the students surveyed depicted personal practices of improper medication storage and disposal. The inappropriate storage and disposal of medications among future well-meaning health care providers may increase the availability of prescription drugs for potential misuse, as many may be naïve to the breadth of $\mu$ : ${ }^{\circ}$ scription drug use. Therefore, a different educational approach may be beneficial in cinging these future health care providers' personal practices and beliefs regarding $\operatorname{pro}_{\uparrow}{ }^{\prime}$ er medication storage and disposal, in order for this to be then translated in patient teaching th fue future patients they encounter (Rashid, 2019).

$\underline{\text { Strengths and Limitations }}$

This study is not without limitatı ns. Lack of generalizability is one. Therefore, repetitive studies conducted at different unive-rit se surveying pharmacy and nursing students, in addition to addressing the issue using a g. bal approach may be beneficial in further transferability of the

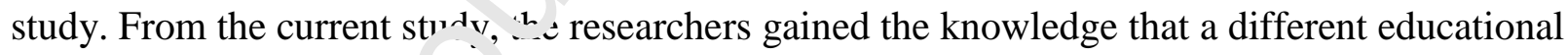
approach for both groups ot students may increase greater understanding and awareness regarding proper medication use and disposal that can be applied in their personal medication use and disposal. Consequently, if this knowledge is perceived to have personal merit and worth, it will likely be transferred into the education of their future patients, thus perhaps impacting healthcare on a larger scale in the future. One future educational strategy would be the incorporation of simulation and role play as an interactive unfolding case study for an interprofessional educational endeavor. 


\section{Conclusion}

This research study involved analysis of 210 pharmacy and nursing students at a large university located within a large city in the U.S. Approximately one third of both groups of students reported not receiving any advice on safe medication storages, and more than half of both groups received no advice on the proper disposal of medications. The study also revealed about half pharmacy students and a quarter nursing students were noted to store medications in an open place reachable by children. Additionally, a large number of participants who kept their medications, "’ated different reasons for doing so. Participants reported different reasons for keeping their me tica ion such as in case they needed them later, not wanting to waste medication, or becaus ? inev were unsure of how to dispose of them. Participants also reported sharing their medications $v$ ith, arents, partners or spouse, friends, or their children.

These statistics are concerning, as parti_, ar $_{1}<$ surveyed will one day be the patient educators on safe drug storage and disposal, and students. olf-reported that they personally do not practice the safe implementation of drug storage and Nisp sal. It is imperative that their understanding is enhanced to not only educate themselves regar $\Perp, \sigma$ i..s health safety concern, but also so they have a personal and workable knowledge in order, one day educate their future patients, ultimately impacting the community at large. A tailored c Jur ational component that can be implemented for both pharmacy and

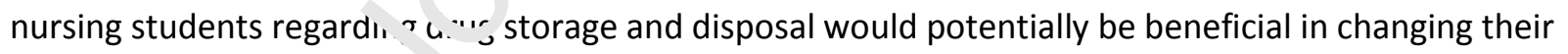
personal practices, with a iullow up survey to note whether or not it was effective. 


\section{Reference}

Bakshi, P., Korey, A., Fowler, W., \& Banga, A. K. (2018). Development and validation of an HPLC-UV method for analysis of methylphenidate hydrochloride and loxapine succinate in an activated carbon disposal system. Journal of Pharmaceutical Analysis, 8(6), 349356.

Buffington, D. E., Lozicki, A., Alfieri, T., \& Bond, T. C. (2019). Understanding factors that contribute to the disposal of unused opioid medication. Journal of pain research, 12, 725.

CDC. (2020). Prescription Drug Use in the United States, 2015-2016. Retrieved from https://www.cdc.gov/nchs/products/databriefs/db334.htm

Drug Enforcement Administration , D. o. J. (2014). Disposal of controlled substances. Final rule. Federal register, 79(174), 53519.

Law, A. V., Sakharkar, P., Zargarzadeh, A., Tai, B. W. B., Hess, F.. Hata, M., . . Park, T. J. (2015). Taking stock of medication wastage: Unused medica. ions in US households. Research in Social and Administrative Pharmacy, 11(4), $5715 \%$.

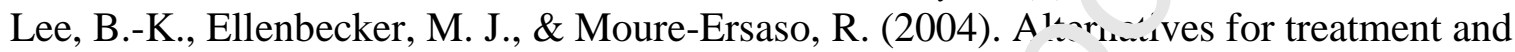
disposal cost reduction of regulated medical wastes. I'ast management, 24(2), 143-151.

Martin, C. B., Hales, C. M., Gu, Q., \& Ogden, C. L. (2019). Prescription drug use in the United States, 2015-2016.

McCabe, S. E., Teter, C. J., Boyd, C. J., Wilens, T. E., \& Schepis, - J. (2018). Sources of Prescription Medication Misuse Among Young Adults in the $\mathcal{i}$ ited States: The Role of Educational Status. The Journal of clinical psychiatry, 79(?), , 7r,11958. https://doi.org/10.4088/JCP.17m1195s

Mitchell, K. J., Nolte, K., Turner, H. A., Hamby, S., \& Jones, L. M. (2018). Exposure to Medication Overdose as an Adversity in Childhı nd. Journal of pediatric nursing, 38, 127-132. https://doi.org/10.1016/j.pedn.? J ᄀ.0..006

Petrik, M. L., McNamara, P. J., Moesc ıle. S. M., \& Blair, B. D. (2019). Communication of Recommendations for the Jisp רsal of Unused Prescription Opioid Medications by Stakeholders in the News Media. Pain . neu "ine (Malden, Mass.), 20(9), 1711-1716. https://doi.org/10.109.'on /pnz104

Raja, S., Mohapatra, S., ' 'эlà'selı ', A., \& Rani, R. J. (2018). Awareness and Disposal Practices of Unused and Expired Medica ion among Health Care Professionals and Students in a Tertiary Care Teaching Hospital. Biomedical and Pharmacology Journal, 11(4), 2073+

Schillie, S. F., Shehab, N., Thomas, K. E., \& Budnitz, D. S. (2009). Medication overdoses leading to emergency department visits among children. American journal of preventive medicine, $37(3)$, 181-187. https://doi.org/10.1016/j.amepre.2009.05.018

Shahbandeh, M. (2020). Total number of retail prescriptions filled annually in the U.S. 20132025. Retrieved from https://www.statista.com/statistics/261303/total-number-of-retailprescriptions-filled-annually-in-the-us/

Tichy, E. M., Schumock, G. T., Hoffman, J. M., Suda, K. J., Rim, M. H., Tadrous, M., . . . Vermeulen, L. C. (2020). National trends in prescription drug expenditures and projections for 2020. American Journal of Health-System Pharmacy, 77(15), 1213-1230. doi:10.1093/ajhp/zxaa116 
Varisco, T. J., Fleming, M. L., Bapat, S. S., Wanat, M. A., \& Thornton, D. (2019). Health care practitioner counseling encourages disposal of unused opioid medications. Journal of the American Pharmacists Association : JAPhA, 59(6), 809-815.e5. https://doi.org/10.1016/j.japh.2019.07.010

Wieczorkiewicz, S. M., Kassamali, Z., \& Danziger, L. H. (2013). Behind closed doors: medication storage and disposal in the home. Annals of Pharmacotherapy, 47(4), 482489. 
Table 1.1. Sample characteristics-education

\begin{tabular}{|c|c|c|c|}
\hline Participants & Field of Education & $\mathbf{N}$ & $\%$ \\
\hline \multirow{5}{*}{$\begin{array}{l}\text { Pharmacy students } \\
N=139\end{array}$} & Professional year in pharmacy school & & \\
\hline & P1 & 17 & 12.2 \\
\hline & $\mathrm{P} 2$ & 31 & 22.3 \\
\hline & P3 & 61 & 43.9 \\
\hline & P4 & 30 & 21.6 \\
\hline \multirow{4}{*}{$\begin{array}{l}\text { Nursing Students } \\
N=71\end{array}$} & Nursing program & & \\
\hline & RN to BSN & 4 & 5.6 \\
\hline & Second degree BSN & 62 & 87.3 \\
\hline & Traditional BSN & 5 & 7 \\
\hline
\end{tabular}

Table 1.2. Sample characteristics-race and ethnicity

\begin{tabular}{|c|c|c|c|c|c|c|}
\hline \multirow[t]{2}{*}{ Variable } & \multicolumn{2}{|c|}{ Pharm.D } & \multicolumn{2}{|c|}{ Nursing } & \multicolumn{2}{|c|}{ Cumulative } \\
\hline & $\mathrm{N}$ & $\%$ & $\mathrm{~N}$ & $\%$ & $\mathrm{~N}$ & $\%$ \\
\hline \multicolumn{7}{|l|}{ Gender } \\
\hline Female & 101 & 73.2 & Es & 88.7 & 164 & 78.5 \\
\hline Male & 37 & 26.8 & 8 & $\perp 1.3$ & 45 & 21.5 \\
\hline \multicolumn{7}{|l|}{ Race/ethnicity } \\
\hline White/Caucasian & 25 & $1 c$ & 29 & 40.8 & 54 & 25.7 \\
\hline African American/Black & 9 & 6.5 & 6 & 8.5 & 15 & 9 \\
\hline Asian & 7 ? & 30.4 & 20 & 28.2 & 90 & 42.8 \\
\hline Hispanic & $? 0$ & 14.4 & 15 & 21.1 & 35 & 16.6 \\
\hline Middle Eastern or North Africar, & 11 & 7.9 & 0 & 0 & 11 & 0.5 \\
\hline
\end{tabular}

Table 2. Opinions on disposal o ' ' Inı sed or expired medications

\begin{tabular}{|l|l|l|l|l|}
\hline Variable & \multicolumn{2}{|l|}{$\begin{array}{l}\text { Pharm.D } \\
\text { (N = 138) }\end{array}$} & \multicolumn{2}{|l|}{$\begin{array}{l}\text { Nursing } \\
\text { (N = 71) }\end{array}$} \\
\hline & $\mathrm{N}$ & $\%$ & $\mathrm{~N}$ & $\%$ \\
\hline $\begin{array}{l}\text { How do you think expired or unused SOLID dosage forms (i.e. tablets, } \\
\text { capsules, suppositories, pessaries, transdermal patches) should be } \\
\text { disposed?* }\end{array}$ & & & & \\
\hline In the trash bin & 46 & 33.1 & 14 & 19.7 \\
\hline In the sink & 0 & 0 & 1 & 1.4 \\
\hline In the toilet & 4 & 2.9 & 4 & 5.6 \\
\hline $\begin{array}{l}\text { In a medication's bin collected by contractors (specialized companies } \\
\text { that collects unused or expired medications, ex. Sharps) }\end{array}$ & 114 & 82 & 61 & 85.9 \\
\hline Sent back to pharmaceutical distributor & 59 & 42.4 & 29 & 40.8 \\
\hline Other & 7 & 5 & 4 & 5.6 \\
\hline How do you think expired or unused LIQUID dosage forms (i.e. & & & & \\
\hline
\end{tabular}




\begin{tabular}{|c|c|c|c|c|}
\hline \multicolumn{5}{|l|}{ suspensions, elixirs, topical lotions, injections) should be disposed?* } \\
\hline In the trash bin & 36 & 25.9 & 10 & 14.1 \\
\hline In the sink & 16 & 11.5 & 14 & 19.7 \\
\hline In the toilet & 9 & 6.5 & 9 & 12.7 \\
\hline $\begin{array}{l}\text { In a medication's bin collected by contractors (specialized companies } \\
\text { that collects unused or expired medications, ex. Sharps) }\end{array}$ & 112 & 80.6 & 55 & 77.5 \\
\hline Sent back to pharmaceutical distributor & 58 & 41.7 & 26 & 36.6 \\
\hline Other & 5 & 3.6 & 4 & 5.6 \\
\hline \multicolumn{5}{|l|}{$\begin{array}{l}\text { How do you think expired or unused SEMI-SOLID preparations (i.e. } \\
\text { creams, ointments) should be disposed?* }\end{array}$} \\
\hline In the trash bin & 50 & 36 & 20 & 28.2 \\
\hline In the sink & 3 & 2.2 & 1 & 1.4 \\
\hline In the toilet & 4 & 2.9 & 4 & 5.6 \\
\hline $\begin{array}{l}\text { In a medication's bin collected by contractors (specialized r uı Janies } \\
\text { that collects unused or expired medications, ex. Sharps) }\end{array}$ & 105 & 75.5 & 55 & 77.5 \\
\hline Sent back to pharmaceutical distributor & 59 & 42.4 & 26 & 36.6 \\
\hline+ & 3 & 2.2 & 2 & 2.8 \\
\hline \multicolumn{5}{|l|}{$\begin{array}{l}\text { How do you think expired or unused Class/Schedule II conc. olled drugs } \\
\text { (i.e. morphine, methylphenidate) of any dosage f( } r^{r} \text {. hould be } \\
\text { disposed?* }\end{array}$} \\
\hline In the trash bin & 7 & 5 & 1 & 1.4 \\
\hline In the sink & 0 & 0 & 3 & 4.2 \\
\hline In the toilet & 4 & 2.9 & 7 & 9.9 \\
\hline 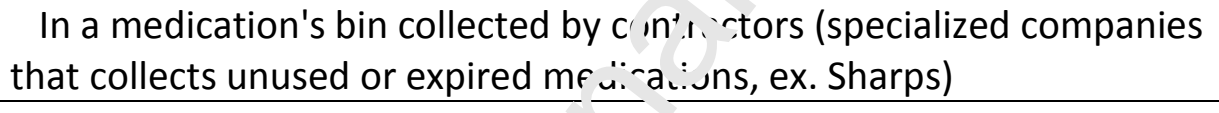 & 108 & 77.7 & 52 & 73.2 \\
\hline Sent back to pharmaceutical d ${ }^{\prime} s_{1}$ : hutor & 64 & 46 & 35 & 49.3 \\
\hline Other & 11 & 7.9 & 6 & 8.5 \\
\hline \multicolumn{5}{|l|}{$\begin{array}{l}\text { How do you think expired o, 'ın sed Class/Schedule III controlled drugs } \\
\text { (i.e. codeine, diazepam) } t \text { aı } \vee \text { dosage form should be disposed?* }\end{array}$} \\
\hline In the trash bin & 10 & 7.2 & 0 & 0 \\
\hline In the sink & 0 & 0 & 3 & 4.2 \\
\hline In the toilet & 3 & 2.2 & 6 & 8.5 \\
\hline $\begin{array}{l}\text { In a medication's bin collected by contractors (specialized companies } \\
\text { that collects unused or expired medications, ex. Sharps) }\end{array}$ & 110 & 79.1 & 52 & 73 \\
\hline Sent back to pharmaceutical distributor & 63 & 45.3 & 37 & 52 \\
\hline Other & 10 & 7.2 & 3 & 4.2 \\
\hline
\end{tabular}

*: participants were able to choose multiple answers, which is why the \% adds up to a number greater than $100 \%$.

Table 3. Source of knowledge related to medication storage and disposal 


\begin{tabular}{|c|c|c|c|c|}
\hline \multirow[t]{2}{*}{ Variable } & \multicolumn{2}{|c|}{\begin{tabular}{|l|} 
Pharm.D \\
( $N=118)$
\end{tabular}} & \multicolumn{2}{|c|}{$\begin{array}{l}\text { Nursing } \\
(\mathrm{N}=61)\end{array}$} \\
\hline & $\mathrm{N}$ & $\%$ & $\mathrm{~N}$ & $\%$ \\
\hline \multicolumn{5}{|l|}{ Did you receive advice on safe medication storage? } \\
\hline Yes & 81 & 68.6 & 41 & 67.3 \\
\hline No & 37 & 31.4 & 20 & 32.8 \\
\hline Where did you receive the most info about safe medication storage?** & 80 & & 41 & \\
\hline Doctor & 2 & 2.5 & 5 & 12.2 \\
\hline Pharmacist & 58 & 72.5 & 18 & 43.9 \\
\hline Nurse & 4 & 2.9 & 11 & 26.8 \\
\hline Journals, Television, Radio & 1 & 1.3 & 0 & 0 \\
\hline Relatives & 2 & 2.5 & 0 & 0 \\
\hline Information leaflets & 15 & 18.8 & 6 & 14.6 \\
\hline Others & 2 & 2.5 & 1 & 2.4 \\
\hline \multicolumn{5}{|l|}{ Did you receive advice on safe medication disposal? } \\
\hline$\infty$ & 62 & 53 & 19 & 31.1 \\
\hline No & 55 & 47 & 42 & 68.9 \\
\hline Where did you receive the most info about safe menicatiol, disposal?** & 61 & & 19 & \\
\hline Doctor & 0 & 0 & 1 & 5.3 \\
\hline Pharmacist & 50 & 82 & 6 & 31.6 \\
\hline Nurse & 0 & 0 & 7 & 36.8 \\
\hline Journals, Television, Radio & 0 & 0 & 1 & 5.3 \\
\hline Relatives & 1 & 1.6 & 0 & 0 \\
\hline Information leaflets & 7 & 11.5 & 3 & 15.8 \\
\hline Others & 3 & 4.9 & 1 & 5.3 \\
\hline
\end{tabular}

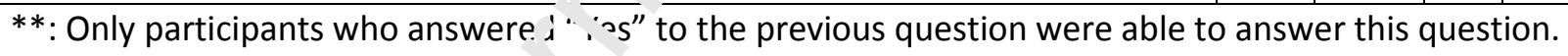

Table 4. Practice on storage ind disposal of medication

\begin{tabular}{|l|l|l|l|l|}
\hline Variable & \multicolumn{2}{l|}{$\begin{array}{l}\text { Pharm.D } \\
\text { (N=115) }\end{array}$} & \multicolumn{2}{l|}{$\begin{array}{l}\text { Nursing } \\
\text { (N = 61) }\end{array}$} \\
\hline Where do you store your medications? & $\mathrm{N}$ & $\%$ & $\mathrm{~N}$ & $\%$ \\
\hline Bathroom & & & & \\
\hline Bedroom & 16 & 13.9 & 23 & 37.7 \\
\hline Kitchen & 38 & 33 & 12 & 19.7 \\
\hline Other & 47 & 40.9 & 24 & 39.3 \\
\hline
\end{tabular}




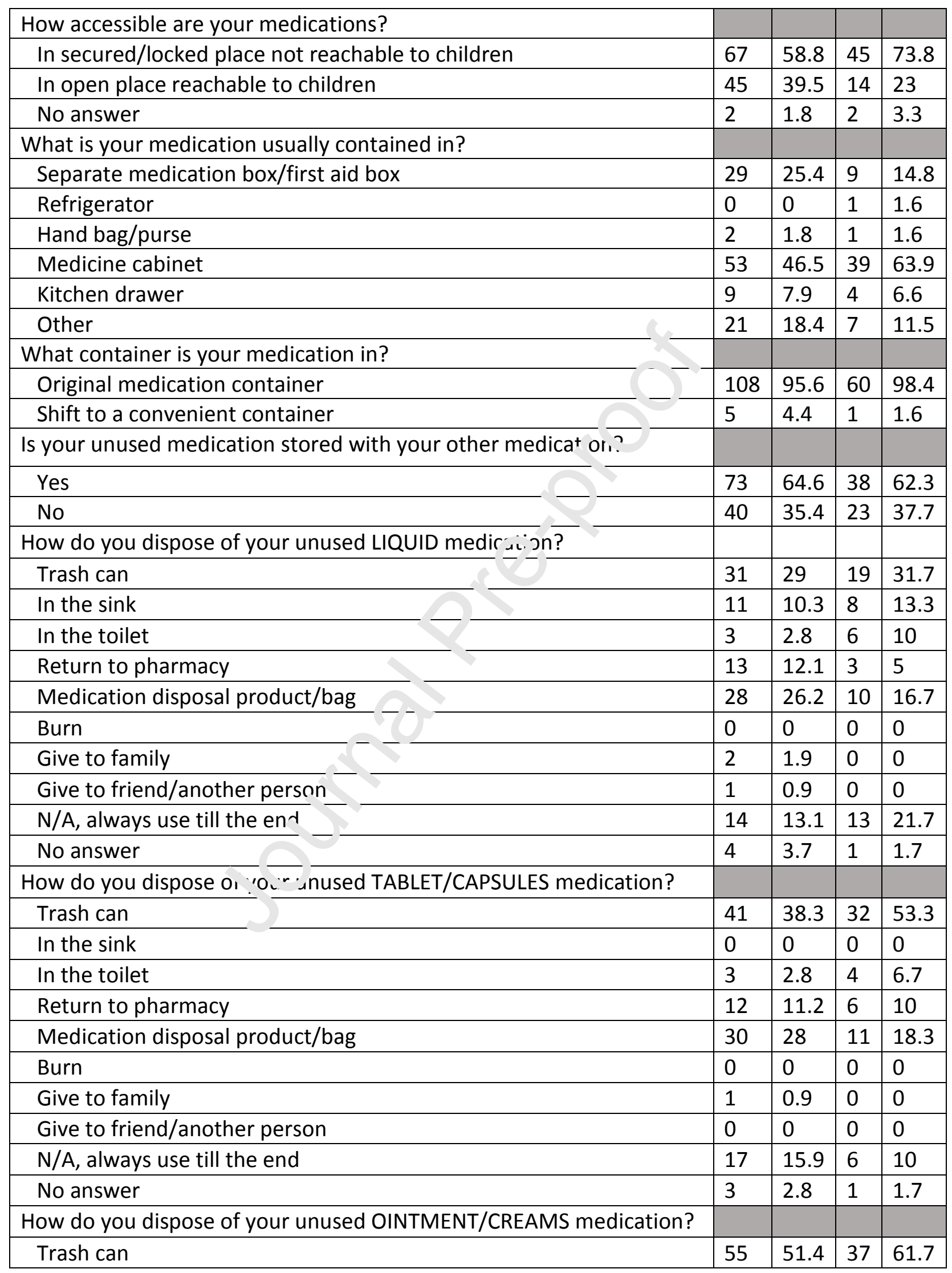




\begin{tabular}{|l|l|l|l|l|}
\hline In the sink & 0 & 0 & 0 & 0 \\
\hline In the toilet & 1 & 0.9 & 0 & 0 \\
\hline Return to pharmacy & 7 & 6.5 & 1 & 1.7 \\
\hline Medication disposal product/bag & 20 & 18.7 & 8 & 13.3 \\
\hline Burn & 0 & 0 & 0 & 0 \\
\hline Give to family & 1 & 0.9 & 0 & 0 \\
\hline Give to friend/another person & 0 & 0 & 0 & 0 \\
\hline N/A, always use till the end & 20 & 18.7 & 11 & 18.3 \\
\hline No answer & 3 & 2.8 & 3 & 5 \\
\hline How are your medications prepared before being discarded? & & & & \\
\hline Crushed & 7 & 6.5 & 4 & 6.7 \\
\hline Diluted & 7 & 6.5 & 2 & 3.3 \\
\hline As they are & 73 & 68.2 & 41 & 68.3 \\
\hline Do not know & 13 & 12.1 & 12 & 20 \\
\hline Other & 7 & 6.5 & 1 & 1.7 \\
\hline & & & & \\
\hline
\end{tabular}

Table 5. Practice of unused medication

\begin{tabular}{|l|l|l|l|l|l|}
\hline Variable & \multicolumn{2}{l|l}{$\begin{array}{l}\text { Pharm.D. } \\
\text { students }\end{array}$} & \multicolumn{2}{l|}{$\begin{array}{l}\text { Nursing } \\
\text { students }\end{array}$} \\
\hline & $\mathrm{N}$ & $\%$ & $\mathrm{~N}$ & $\%$ \\
\hline Do you have leftover/unused me catiun at home? ${ }^{* *}$ & 126 & & 64 & \\
\hline Yes & 75 & 59.5 & 28 & 43.8 \\
\hline No & 47 & 37.3 & 35 & 54.7 \\
\hline Do not know & 4 & 3.2 & 1 & 1.6 \\
\hline Where did you obtain yo r medication? $^{*}$ & 68 & & 26 & \\
\hline Prescribed by provide & 52 & 76.5 & 20 & 76.9 \\
\hline Purchased as OTC & 13 & 19.1 & 6 & 23.1 \\
\hline A friend/family gave unused medication & 3 & 4.4 & 0 & 0 \\
\hline Do you know what your medication(s) is/are for? & & & & \\
\hline Yes & 67 & 98.5 & 26 & 100 \\
\hline No & 1 & 1.5 & 0 & 0 \\
\hline What are the dosage form(s) of your medication? * & & & & \\
\hline Tablets/capsules & 60 & 88.2 & 24 & 92.3 \\
\hline Drops/syrups & 2 & 2.9 & 1 & 3.8 \\
\hline Topical preparations & 11 & 16.2 & 2 & 7.7 \\
\hline Inhalers & 2 & 2.9 & 2 & 7.7 \\
\hline
\end{tabular}




\begin{tabular}{|c|c|c|c|c|}
\hline Injections & 0 & 0 & 0 & 0 \\
\hline Others & 1 & 1.5 & 0 & 0 \\
\hline Reasons for not using all of your medication * & 68 & & 26 & \\
\hline Change to another treatment & 15 & 22.1 & 7 & 26.9 \\
\hline Discontinued by provider & 8 & 11.8 & 5 & 19.2 \\
\hline Excess quantity supplied & 27 & 39.7 & 11 & 42.3 \\
\hline Inconvenience/difficult instructions & 2 & 2.9 & 1 & 3.8 \\
\hline Condition improved/resolved & 30 & 44.1 & 6 & 23.1 \\
\hline Patient deceased & 0 & 0 & 1 & 3.8 \\
\hline Past expiration date & 9 & 13.2 & 7 & 26.9 \\
\hline Forgetfulness & $\therefore$ & 4.4 & 2 & 7.7 \\
\hline Side effects & 8 & 11.8 & 7 & 26.9 \\
\hline Medication labels unclear & $\overline{0}$ & 0 & 0 & 0 \\
\hline Other & 9 & 13.2 & 4 & 15.4 \\
\hline Reasons for keeping your unused medication * & 68 & & 26 & \\
\hline Does not want to waste medication & 21 & 30.9 & 9 & 34.6 \\
\hline In case medication is needed later & 48 & 70.6 & 13 & 50 \\
\hline Not sure how to dispose & 8 & 11.8 & 9 & 34.6 \\
\hline To give away to others & 4 & 5.9 & 0 & 0 \\
\hline To keep a stockpile in case of shortage & 10 & 14.7 & 2 & 7.7 \\
\hline+2 & 12 & 17.6 & 7 & 27 \\
\hline $\begin{array}{l}\text { Do you collect all prescribed medicaticn even i. you decide } \\
\text { that you do not need some of it? }\end{array}$ & 115 & & 61 & \\
\hline Yes & 57 & 49.6 & 36 & 59 \\
\hline No & 58 & 50.4 & 25 & 41 \\
\hline \multicolumn{5}{|l|}{$\begin{array}{l}\text { Do you collect all refills even if, iu aecide that you do not } \\
\text { need them? }\end{array}$} \\
\hline$-\infty$ & 25 & 21.7 & 10 & 16.4 \\
\hline-1 & 88 & 76.5 & 51 & 83.6 \\
\hline Prefer not to answer & 2 & 1.7 & 0 & 0 \\
\hline \multicolumn{5}{|l|}{ Do you share your medication with others? $* * *$} \\
\hline Yes & 15 & 22.4 & 3 & 11.5 \\
\hline No & 52 & 77.6 & 23 & 88.5 \\
\hline Share medication with $* *$ & 15 & & 3 & \\
\hline Parents & 10 & 66.7 & 2 & 66.7 \\
\hline Husband/wife/partner & 3 & 20 & 1 & 33.3 \\
\hline Siblings & 7 & 46.7 & 3 & 100 \\
\hline Friend & 4 & 26.7 & 0 & 0 \\
\hline Child & 0 & 0 & 1 & 33.3 \\
\hline Other & 0 & 0 & 0 & 0 \\
\hline
\end{tabular}

*: participants were able to choose multiple answers, which is why the $\%$ adds up to a number greater than $100 \%$. 
**: Only participants who answered "Yes" to the previous question were able to answer this question. ***: Only participants who answered "Yes" to "Do you have leftover/unused medication at home" were able to answer this question 
Author statement:

Tamara Al Rawwad: Conceptualization, Methodology, Writing- Original draft preparation, Formal analysis, Writing- Reviewing and Editing

Patrici K. Schrader: Investigation, Writing- Original draft preparation, Writing- Reviewing and Editing Andrea Brooks: Investigation, Writing- Original draft preparation, Writing- Reviewing and Editing Lillian Duong: Writing- Original draft preparation, Formal analysis

Douglas Thornton: Funding acquisition, Writing- Reviewing and Editing 